\title{
MULTI-HAZARD RISK ASSESSMENT IN URBAN PLANNING AND DEVELOPMENT USING AHP
}

\author{
A. Sharma ${ }^{1}$ H. Miyazaki ${ }^{1}$ \\ ${ }^{1}$ Asian Institute of Technology, Remote Sensing and Geographic Information System, Department of Information and \\ Communications Technology
}

Commission VI, WG VI/4

KEYWORDS: Multi-hazard risk assessment, Analytical Hierarchical Procedure (AHP), Land-use planning, Madang Province

\begin{abstract}
:
Many cities across the world are exposed to more than one hazards. Focus on only the most prominent natural hazards, or the most recent event can be dangerous, as many potential threats to urban development are not assessed. Even when multiple hazards in a given area is assessed, there is a lot of confusion on how to utilize hazard information in making decisions for urban land-use planning. This study is aimed to develop a method to utilize hazard maps in urban land-use decision making. The study has identified numerous applications of GIS-based multi-criteria decision model (MCDM) for land-use suitability evaluation. It has then tried to integrate multiple hazard maps, a product of multi-hazard risk assessment, into the model to generate suitability maps for further development. The used parameters were correlated using the Analytical Hierarchical Process (AHP), one of the MCDM tool and incorporated into the GIS environment, with a comparison between the cases with- and without-hazard considerations. The application of the proposed method was tested for Madang Province, Papua New Guinea for four land-uses, i.e., residential, industrial, commercial, and agricultural. The results of the model i.e., land-use suitability maps were spatially reflective of the model user's decisions and understanding. This model gave considerable results for the urban development plan. Furthermore, comparison of the model outputs with and without hazard considerations led to notable differences. For example, almost $1 \%$ of the study area was rendered unsuitable for residential development in the assessment without hazard consideration. Besides, approximately $14 \%$ of the study area were assessed as suitable for without-hazard consideration but less suitable for with-hazard consideration. Since the hazard maps represented patterns and locations of natural hazards, our approach of incorporating them could help highlight the gaps in risk recognition with future development in hazardous areas.
\end{abstract}

\section{INTRODUCTION}

\subsection{Background}

1.2 Urban land-use is guided by several factors such as its physical environment, demographics, financial growth, political stability, and natural hazards. However, during urban planning and development, more emphasis is given to social and economic factors. Usually, the city's or region's vulnerability to hazards is not properly assessed. Hence, in areas which lie in a rugged landscape, seismically active zones or low-lying area, natural hazards such as landslide or earthquake can occur frequently. This can cause severe damage to human lives and their property (Bathrellos, G.D. 2017). To avoid such scenarios, urban planners, decision-makers, engineers, policymakers should consider not only the physical environment of the study area but also its susceptibility to natural hazards (Bathrellos, G.D., 2008).

Another important issue in this context is also that most cities are exposed to more than one hazard (Dilley et al., 2005). Therefore, we need to address the causes and consequences of all potential hazards to assess the risks and impacts of multihazards to a city (V Gallina et al., 2016). In this regard, the multi-hazard approach helps understand how hazards and vulnerabilities are combined over territory and gives a more accurate representation of the complexity of the risks for an area (Carpignano, A et al., 2009).

To deal with natural hazards, it is first necessary to identify different hazard sources and conduct a detailed hazard assessment. Nevertheless, hazard information alone is insufficient; sometimes more effective land-use decision making should be undertaken to reduce human pressure in hazard-prone areas to lessen the exposure. However, urban planners are often faced with challenges in interpreting the information in the hazard maps because such information is provided only in terms of probability or estimated frequencies, whilst other indicators such as the spatial location of triggering phenomena, extension of potentially impacted areas, expected severity and duration, are often neglected (Galderisi, A., \& Menoni, S. (2016). Therefore, the main objective of this research is to develop an approach to integrate the information derived from multi-hazard assessments into the land-use planning decision-making.

There are many decision support tools in urban planning; landuse suitability assessment is one of the oldest tools. Land-use suitability assessment is a combination of Geographic Information System (GIS) and Multi-Criteria Decision Making (MCDM). This tool has been used by researchers and urban planners to make different decisions related to urban planning such as the selection of best locations for housing infrastructures (Dai et. al, 2001), identification of restrictions and possibilities of urban expansion (Yang, F., 2008), identification of suitable areas for industrial development (Bathrellos, GD, 2011) Most of the time, these assessments do not take account of potential hazards in the area. To fill this gap, this paper has tried to integrate hazard information into an existing land-use suitability assessment model. It has used the Pairwise comparison, Analytical Hierarchical Process (AHP) as a Multi-Criteria Decision Making (MCDM) tool developed by Saaty (1980). This study has tested the applicability of the 
model by using the Madang province of Papua New Guinea as a case study. The output of such assessment was land-use suitability maps that could be a basis for urban planners to make informed decisions in land-use planning.

\section{METHODOLOGY}

This study is aimed to develop a method to utilize hazard maps in urban land-use decision making. The study has identified numerous applications of GIS-based multi-criteria decision model (MCDM) for land-use suitability evaluation. It has then tried to integrate multiple hazard maps, a product of multihazard risk assessment, into the model to generate suitability maps for further development. The used parameters were correlated using the Analytical Hierarchical Process (AHP), one of the MCDM tool and incorporated into the GIS environment, with a comparison between the cases with- and without-hazard considerations.

\subsection{Definition of Suitability}

Each landscape has unique properties and is to some degree suitable or unsuitable for any intended activity. In this paper, we follow the definition from Hopkins (1977) and Collins et al (2001) which suggest that land-use suitability assessment aims to identify the most appropriate pattern for future land-use.

\subsection{Factors that Affect Land-use Suitability}

Selection of factors that affect land-use suitability are not universal. The landscape and ground conditions affect development, new construction, and environmental quality. Steep slopes and varying topographic gradients are susceptible to erosion this might affect site access and development feasibility (Ohri et al. 2010, 108). While these are some commonly used factors that influence land-use decisions, they are not exhaustive and may vary upon the interest group and land-use. (Zhang et al, 2015).

2.2.1 Residential land-use: Halden et al (2002) explored the concept of accessibility to public transport, employment, health, and social care, education, and leisure facilities, amongst other services. The major utility services that have an influence on land-use planning were identified as roads, power supply, water supply, and sewerage facilities. Existing land-use is a major foundation where future land-use maps are made. It is necessary for future land-use to co-exist with neighbouring use/activity without causing significant adverse effects (Q Hang, 2012). The topography of land greatly affects the application of its use. Constructing housing development projects on steep land is relatively more difficult than in flat land, because of the increased cost of construction for earthwork, excavation to make the steep land flat (Anderson et al., 1976). City centres, major towns were considered as a potential workplace that facilitates residential land-uses.

2.2.2 Industrial Land-use: Industries need utilities and infrastructure for proper operation. Clean water for daily use, wastewater facilities for industrial effluents, accessible to communities from where they can gather labour forces, availability of inexpensive energy, good transportation network are some utilities identified for day to day operations of industries (Steiner and Butler, 2007, Bowen Jr. 2008).

It is advised to locate the industries far away from priority habitat areas because human activities and construction work can affect the natural state of the forest and wetlands (M Berube 2014).

2.2.3 Commercial Land-use: Population density indicates the availability, accessibility, or the presence of local markets, thus can be integral in determining potential land-use (Agarwal C et al. 2002 and Allen, J.2003). The built environment is largely a function of existing land-use. The nature of existing land-use neighbourhoods affects the land-use changes, for example, the possibility of urbanization of expansion is mostly related to the neighbourhood (Cheng, J, 2005). Among other factors, accessibility significantly influences economic and human activities. Yang Z.S (2015) states that transportation accessibility plays an important role in shaping the spatial structure of the city, which also creates and shapes economic and social opportunities, essential for the commercial area (C Sun, 2016)

2.2.4 Agricultural Land-use: As cited in the Report of Agricultural System of Madang Province, sites on flatter land are more likely to be more fertile, but perhaps have poorer drainage than those on sloping land (R Michael Bourke, 2009). In the highlands of PNG, mixed vegetable food gardens are typically planted on flatter and more fertile land, while the sweet potato is commonly planted on better-drained sites, which are often on a gentle to a steep slope. Temperature and light are critical determinants of the plant. In PNG, a country of high mountains, altitude is a major influence on maximum and minimum temperatures and cloud cover (M Berube 2014).

2.2.5 Hazard Risk Considerations: Natural hazards can produce damage to both the natural and man-made environment. In order to minimize the loss of human life and reduce the economic consequences, it is important to consider the natural hazard maps during the land-use stage, The studies of Bathrellos et al 2009, Simeonova SD et al, (2006); Guzzeti et al., 1999, Van Westen, C.J. (1993); reveal that maps that provide spatial information in the distribution of natural hazards such as landslide, floods earthquake are important tools for planners and environment managers while selecting favourable location for land-use development.

\subsection{Analytical Hierarchical Process (AHP) as an MCDM Tool}

Multi-criteria analysis is the decision support tools when there are complex and multiple factors that affect a decision. Multicriteria decision making is a well-known method to handle land-use suitability assessment. Since each factor has its level of importance for different interest groups involved, weighting them can be tough. Multi-criteria techniques can be used to solve this problem.

Among several MCDM, in AHP the comparisons are made using a scale of absolute judgment between 1 to 9 that represents how much more; one factor dominates another concerning a given attribute (Saaty,2007). AHP was chosen for the study because the weighting in AHP through pairwise comparison is much better than a direct assignment of weight because it has an advantage of checking the consistency of the weight by calculating the ratio of consistency ratio and can deal with the inconsistent result.

The usefulness of AHP, to support decision making for land-use suitability, is also that it helps to evaluate problems when one is faced with several conflicting criteria (Beinat and Nijkamp, 
1998); and its ability to address the opinion of multiple interest groups (Antunes et al., 2006).

2.3.1 Hierarchy Formation: In order to apply the AHP method to conduct land-use suitability analysis, it is necessary to break unstructured problems into its component factors. So, the factors were classified into three hierarchies of goal, criteria, and sub-criteria as depicted in Figure 1. Now, the factors were compared against each other and assigned a relative dominant value between 1 and 9 based on the Saaty's scale.

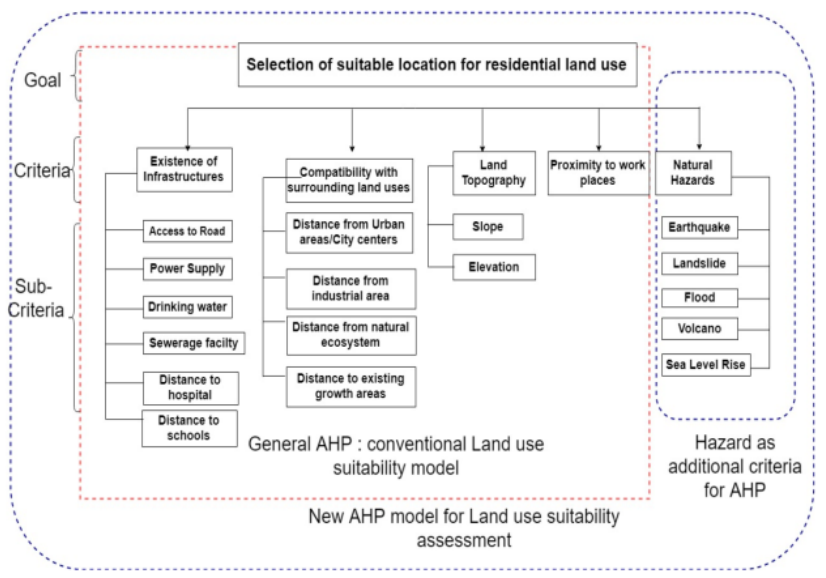

Figure 1. A hierarchical model setup in SuperDecisions for residential land-use suitability

Note: The AHP model without hazard will be referred to as General AHP and AHP with hazard as an additional criterion will be referred to as Multi-hazard AHP

\section{EXPERIMENT}

\subsection{Study area}

Madang is a province on the northern coast of mainland Papua New Guinea. With some of the country's highest peaks and active volcanoes, Madang province exhibits great geographic diversity. The province is comprised of 6 districts and nineteen Local Level Government (LLGs). Madang has a total land area of $29,066 \mathrm{~km}^{2}$, and about 493,906 inhabitants resulting in a population density of 16.99 people per $\mathrm{km}^{2}$. The capital of Madang province is the Madang town, which is an urban centre and a hub for trade and businesses, revenues and jobs derived from the province. The highest peaks rise to $4300 \mathrm{~m}$ above mean sea level. Most of the land is Madang is covered in forest and remains inaccessible accessible due to the ruggedness of the terrain (YA Bun, 2006).

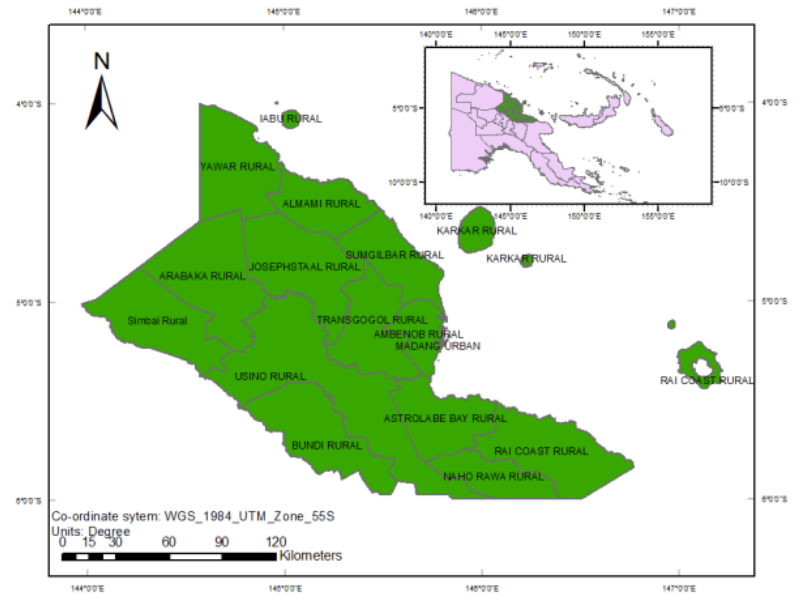

Figure 2. Location map of Madang province, Papua New Guinea

\subsection{Data Acquisition and Processing}

3.2.1 GIS Datasets: While some GIS base maps were acquired through different organizations and global data sources, some base maps have been created based on literature review.

\subsection{Standardization of Hazards}

Different hazards are different in nature. To compare different hazard in one platform, it was necessary to bring them in a common classification scheme. In this study, each hazard has been classified into standard classes of low, medium, high, and very high hazard based on the degree of its intensity and potential losses that each hazard can impose on each land-use [Nollet, M.-J. (2018), Moel, H. de, Szewczyk, W. (2017), Jenkins et al 2015]. Subsequently, the importance of hazards was compared and consequences for the spatial planning process can were defined (Delmonaco et al. 2006b).

\section{RESULTS}

A primary issue in the land-use suitability evaluation is to assign weights to each factor separately. For each land-use category, a set of relative weights for influential factors has been calculated in Super decisions platform. These weights have been used as an input for suitability evaluation in the next step. In this section, the importance of weight or influence weight of each factors resulting from AHP assessment has been presented, followed by the suitability maps resulting from landuse suitability model.

\subsection{Residential Land-use Suitability Assessment}

The AHP requires selected participants to rank the criteria based on pairwise comparison. Each participant was asked to rank the criteria and sub-criteria by referring to the numerical scale. 10 participants were asked to rank the importance of each criterion. The analysis was carried out by using aggregated individual preferences, which were calculated based on geometric means of individual expert's rate for each criterion (Aczel and Saaty, 1983) and Ananda and Herath. 2008). Given below are the influence weight or importance weight of each factors. 


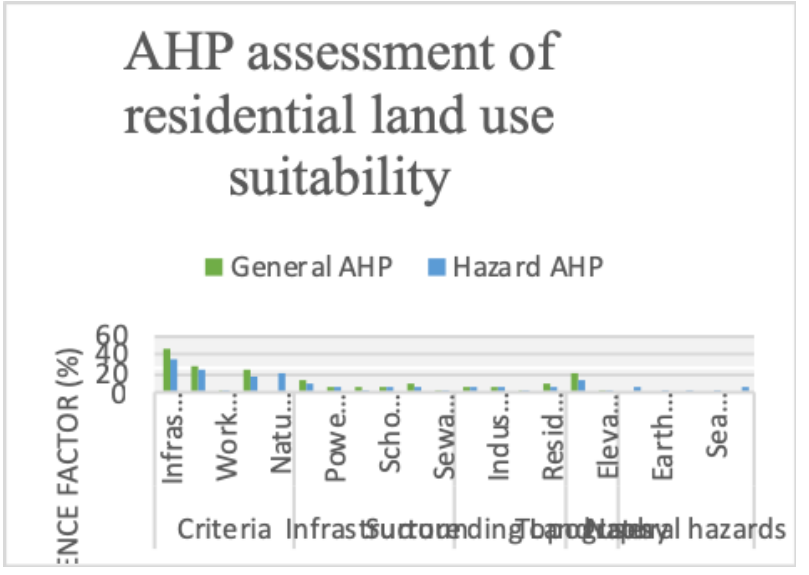

Figure 3. AHP weights of residential land-use suitability assessment

4.1.1 General AHP for Residential Land-use: Existence of infrastructure was the most important criteria with $45 \%$ influence weight. Since residential land-use is targeted for a comfortable way of living, urban planners gave more preference to this criterion. The infrastructures selected were basic facilities like roads, water, power supply, hospitals, and schools. Out of infrastructures $(45 \%)$, it was found that roads $(11 \%)$ and drinking water $(10 \%)$ were prioritized more than others. The second most important factor was Compatibility with surrounding land-uses with $26 \%$ influence weight. Among the four criteria, proximity to workplaces like urban centres or small markets had the least score of $4 \%$. Among all subcriterion, Slope was valued the most with $19 \%$ influence weight. Respondents thought that the elevation of the study area might not have a great impact on the residential land-use category.

4.1.2 Multi-hazard AHP for Residential Land-use: When the hazard factors were synthesized in the AHP model, the influence weight of the criteria and sub criterions have shifted. Proximity to natural hazards alone had an influence weight of $19 \%$. This has caused a reduction in influence weight of other factors, infrastructure has reduced from $45 \%$ to $36 \%$, and the soil topography has reduced from $23 \%$ to $16 \%$. Existence of infrastructure remains the most important criterion, followed by the compatibility with of surrounding land-uses. With an influence weight of $5.83 \%$, flood hazard was thought to have more impact on the different hazards. Sea level rise had the lowest influence weight of $0.17 \%$. Among all sub-criteria, access to road $(9.53 \%)$ and drinking water $(8.10 \%)$, slope $(13.84 \%)$ and the proximity to other residential areas $(7.98 \%)$ seem to have the highest influence weight in residential suitability.

4.1.3 Residential Land-use Suitability Maps: A GIS-based land-use suitability model was prepared in Model Builder in ArcGIS. There are two model inputs that are fed into the model a) GIS layers b) importance/priority weight as derived from AHP. This model uses the sieve mapping technique in GIS to overlay several GIS layers to formulate a final suitability map. This model allows users to assign various weights of importance to different suitability criteria. By applying the weighted overlay, a composite map was produced Each pixel in of composite map now has a suitability score.

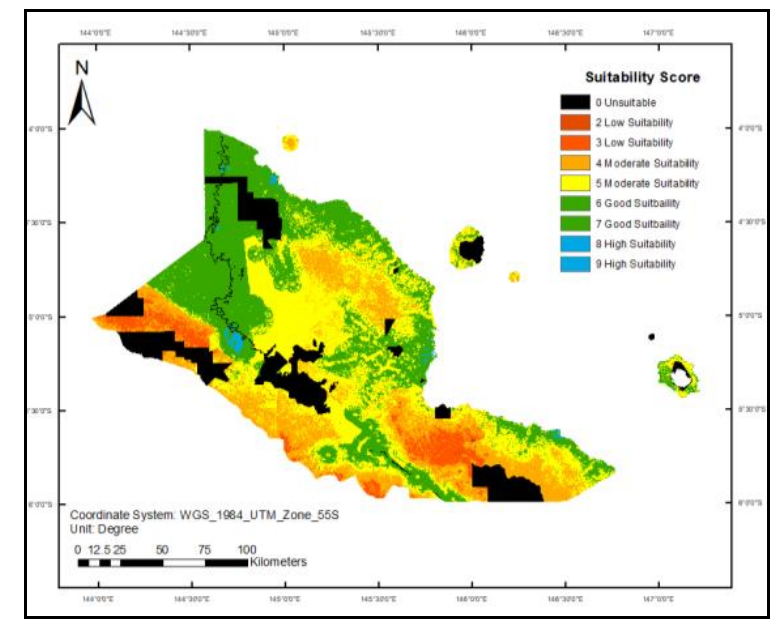

Figure 4. Residential land-use suitability map of general AHP

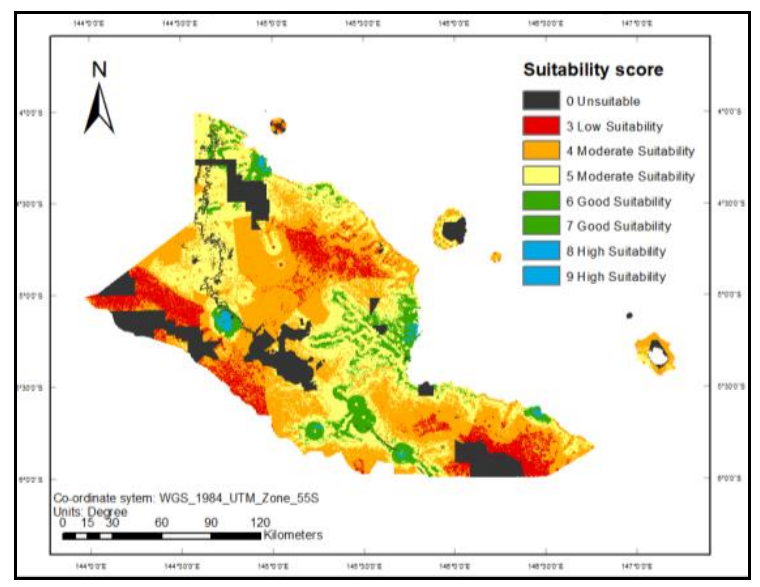

Figure 5. Residential land-use suitability map of Multi-hazard AHP

Table 1. Residential land-use coverage for different degree of suitability

\begin{tabular}{|l|r|r|r|r|}
\hline \multirow{2}{*}{$\begin{array}{l}\text { Suitability } \\
\text { Class }\end{array}$} & \multicolumn{2}{|c|}{ General AHP } & \multicolumn{2}{c|}{ Multi-hazard AHP } \\
\cline { 2 - 5 } & $\begin{array}{c}\text { \% } \\
\text { Coverage }\end{array}$ & Sq. Km & $\begin{array}{c}\text { \% } \\
\text { Coverage }\end{array}$ & Sq. Km \\
\hline Unsuitable & 12.91 & 3742.85 & 13.612 & 3946.27 \\
\hline $\begin{array}{l}\text { Low } \\
\text { Suitability }\end{array}$ & 5.004 & 1450.75 & 19.273 & 5587.51 \\
\hline $\begin{array}{l}\text { Moderate } \\
\text { Suitability }\end{array}$ & 49.062 & 14224 & 41.1 & 11915.74 \\
\hline $\begin{array}{l}\text { Good } \\
\text { Suitability }\end{array}$ & 32.511 & 9425.55 & 25.574 & 7414.52 \\
\hline $\begin{array}{l}\text { High } \\
\text { Suitability }\end{array}$ & 0.513 & 148.72 & 0.441 & 127.87 \\
\hline
\end{tabular}

The table above demonstrates the change in percentage of land with different degree of suitability in two scenarios. Since hazard has a negative influence on the suitability score, the combined percentage of land with good suitability, moderate and high suitability has decreased by $14 \%$ and the percentage of land that is unsuitable or has low suitability has increased by the same number. The percentage of land that is unsuitable for residential purpose has increased by somewhat around $1 \%$. 


\subsection{Industrial Land-use Suitability assessment}

\section{AHP assessment of industial land use suitability}

n General AHP $\quad$ AHP with Hazard consideration

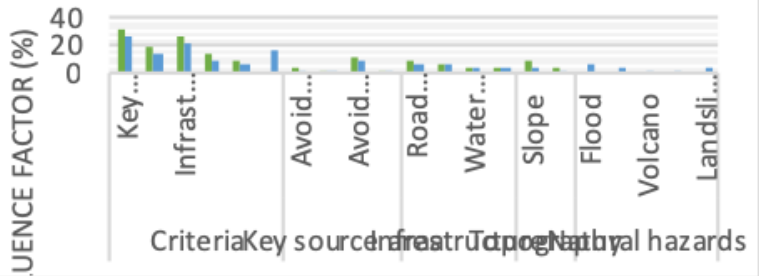

Figure 6. AHP weights of land-use suitability assessment for industrial land-use

4.2.1 General AHP for Industrial Land-use: The most important criteria for industrial land-use was identified as Proximity to key source area with an influence weight $31 \%$. One of the reasons for this was highlighted to reduce the cost of operation by minimizing transportation cost. For this study area, the main industries were selected as extraction industries, marine industries, and logging areas. The second most important criteria is the Existence of infrastructure with almost $26 \%$ influence weight. Road network and power supply were identified as the most important infrastructures. Since industrial wastes tend to have an adverse environmental impact, the experts also mentioned that it is necessary to have sewage facilities for proper disposal of industrial waste and to make sure that they were away from water bodies. If the criterions are compared, one of the most important criteria is to avoid industrial development near urban areas (12\%) followed by access to the road network $(9 \%)$ and slope criterion $(9 \%)$. Experts pointed out that the industrialists prefer to construct industries in areas where the price of land is very low or lands that are barren, but this may contradict with other environmental or social factors.

4.2.2 Multi-hazard AHP for Industrial Land-use: Once the hazard component was introduced, it was identified as the second most important criteria with an influence weight $28 \%$ even more important than the existence of infrastructures. This is attributed to the fact a disaster event can affect the tangible asset of industries such as structural damage to industry and goods and also affect employment generation. Among many hazards, the flood was considered most dangerous to industries with influence weight $8 \%$ followed by earthquake and landslide about $6 \%$ each.
4.2.3 Industrial Land-use Suitability Maps: From the table and figure, it is evident that there are some changes in the land area for industrial land-use. Even though the potential rating was done on a scale from 1 to 9 , the model resulted in a map with the highest suitability score 8 . However, the percentage of low suitability has increased from $5.77 \%$ to $10.16 \%$. There has been a reduction in the percentage of high and good suitability land to some extent. The percentage of unsuitable or not permitted land was also increased because of some restriction, that was fed into the model. For example, restrict to construct within the flood zone or ecologically sensitive zones. The restricted zones are color-coded black.

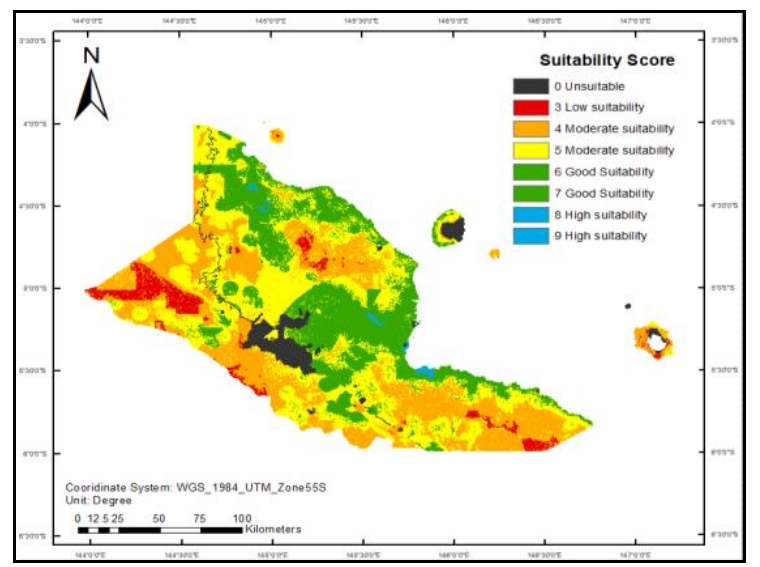

Figure 7. Industrial land-use suitability map with general AHP

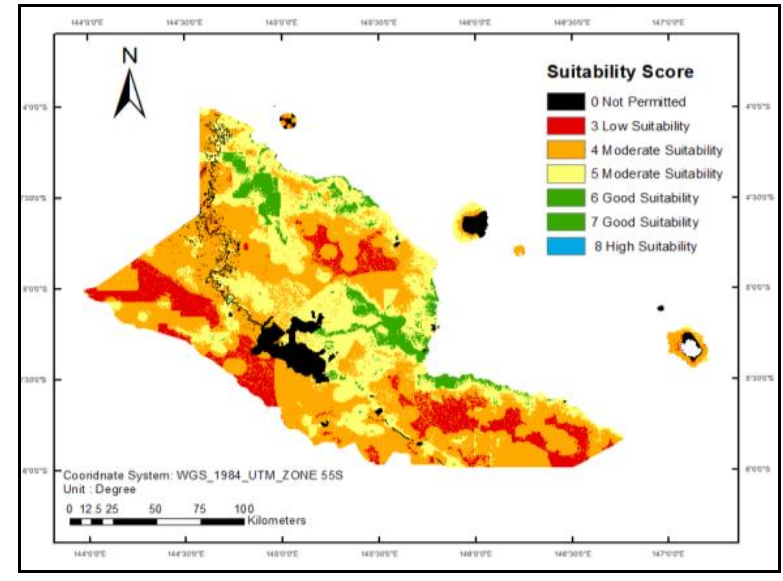

Figure 8. Industrial land-use suitability map of Multi-hazard AHP

Table 2. Industrial land-use coverage for different degree of suitability

\begin{tabular}{|l|r|r|r|r|}
\hline \multirow{2}{*}{$\begin{array}{l}\text { Suitability } \\
\text { Class }\end{array}$} & \multicolumn{2}{|c|}{ General AHP } & \multicolumn{2}{c|}{ Multi-hazard AHP } \\
\cline { 2 - 5 } & 1375.51 & 4.74 & 1582.96 & 5.46 \\
\hline Unsuitable & 1673.46 & 5.77 & 2945.58 & 10.16 \\
\hline $\begin{array}{l}\text { Low } \\
\text { suitability }\end{array}$ & 19501.39 & 67.27 & 18838.94 & 64.98 \\
\hline $\begin{array}{l}\text { Moderate } \\
\text { suitability }\end{array}$ & 6380.92 & 22.01 & 5578.04 & 19.24 \\
\hline $\begin{array}{l}\text { Good } \\
\text { suitability }\end{array}$ & 60.62 & 0.21 & 46.39 & 0.16 \\
\hline $\begin{array}{l}\text { High } \\
\text { suitability }\end{array}$ & & & & \\
\hline
\end{tabular}




\subsection{Agricultural Land-use Suitability Assessment}

4.3.1 General AHP for Agricultural Land-use: In determining the agricultural suitability, the quality of soil or soil fertility was considered the most important factor $(30.44 \%)$. The slope of the land $(12.38 \%)$, and the proximity to water bodies $(15.84 \%)$ were also a dominating factor for agricultural suitability. Since crop productivity is greatly affected by the climatic conditions, the climate was the second most influencing factor for agricultural land-use with a weight of $21.48 \%$ with equal importance of $10.74 \%$ in both temperature and rainfall. The presence of infrastructures does not affect the physical suitability of agriculture; however, it was preferred that the agricultural lands had some connectivity to roads and access to market facilities where farmers can trade their produces. Therefore, roads were assigned a weight of $5.32 \%$ and proximity to marketplaces was $7.87 \%$.

4.3.2 Multi-hazard AHP for Agricultural Land-use: The hazard component also had a great influence weight. But according to experts, out of many hazards, volcanic hazard had the highest influence weight of 5\%. Agriculture is affected by several hydro-meteorological hazards like droughts and cyclones, but these were not included in the study. Flood and landslide with around 3\% weight were thought to be the second most severe hazard. The respondents had a common view that the effect of natural hazards on agriculture is based on the time of occurrence. For example, a flood can cause harms to the crop, if it takes place during the cropping or harvesting period. However, flood instances have known to increase the fertility of the soil because it carries with it, different minerals along the flood plains and can be beneficial to agriculture. The normal practice is the active flood plains or hazard-prone areas are allocated for agricultural land-use because the agricultural sector is the easiest to recover compared to other sectors like commerce or industry. The respondents argued on the effect of the volcano on agriculture. While some think that the minerals present in volcanic ash increase the soil fertility, some defer that survival of crops and pastures is severely limited when there is thick deposition of volcanic ash. The effect of the earthquake and sea-level rise in agriculture was around $1 \%$ which was negligible compared to other criterions.

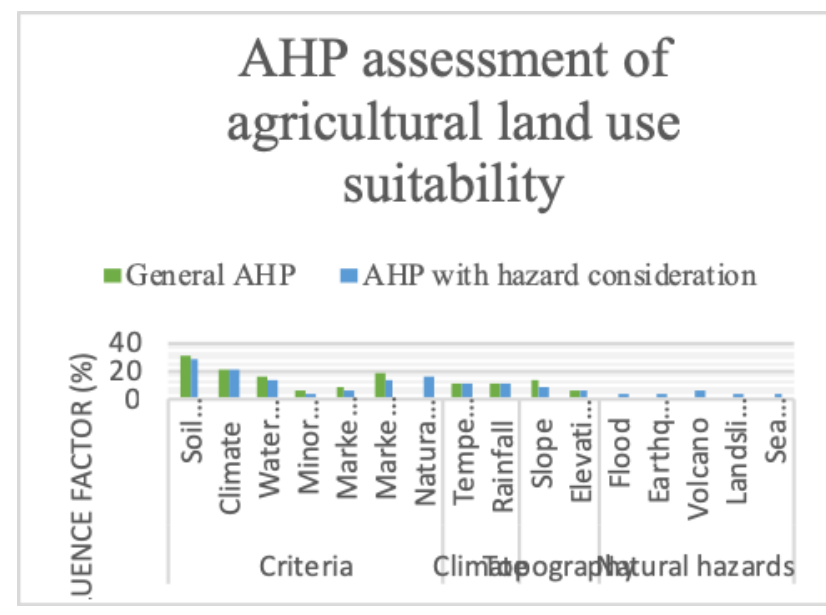

Figure 9. AHP weights of land-use suitability assessment for agricultural land-use
4.3.3 Agricultural Land-use Suitability Maps: The comparative analysis of agricultural land-use yielded slightly different results from residential and industrial land-uses. As shown in the figure below: a significant area of moderate suitability was found to change to low suitability. The percentage area of high suitability and good suitability land was found to increase in contradiction to other land-uses. This is because it was thought that the agricultural sector has a comparatively lesser impact due to Hazards. Annual floods even though, they can destroy the crops, flood events are known to increase the fertility of the soil. Most of the area in Madang was found to have good suitability for agriculture.

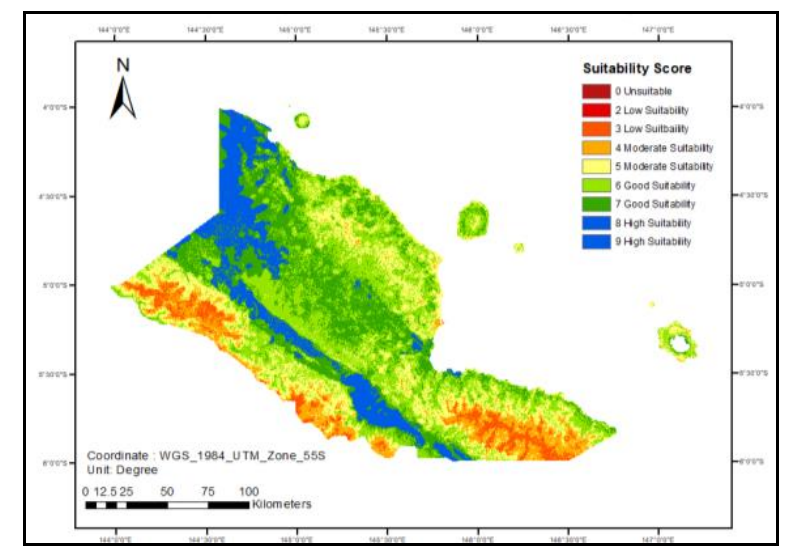

Figure 10. Agricultural land-use suitability map of general AHP

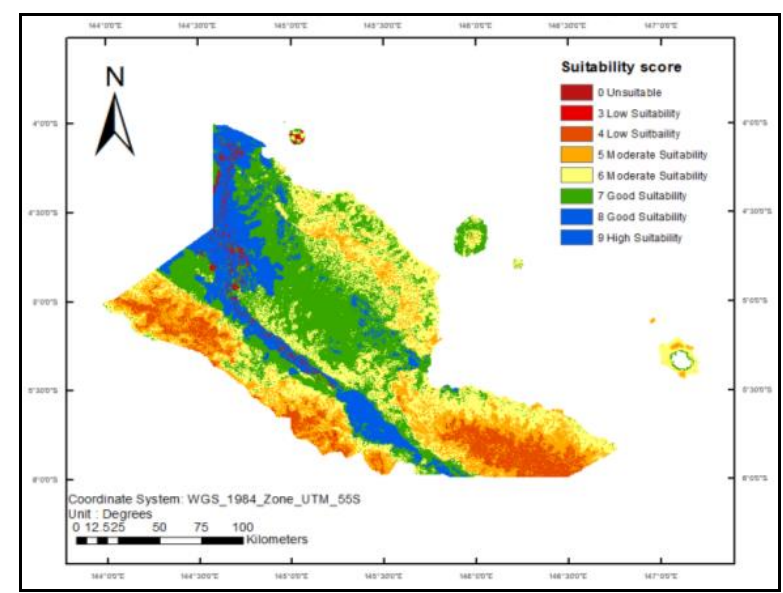

Figure 11. Agricultural land-use suitability map of Multi-hazard AHP

Table 3. Agricultural land-use coverage for different degree of suitability

\begin{tabular}{|l|r|r|r|r|}
\hline \multirow{2}{*}{$\begin{array}{l}\text { Suitability } \\
\text { Class }\end{array}$} & \multicolumn{2}{|c|}{ General AHP } & \multicolumn{2}{c|}{ Multi-hazard AHP } \\
\cline { 2 - 5 } & Sq. Km & \%Coverage & Sq. Km & \%Coverage \\
\hline Unsuitable & 1.98 & 0.01 & 396.24 & 1.367 \\
\hline $\begin{array}{l}\text { Low } \\
\text { suitability }\end{array}$ & 1177.02 & 4.06 & 2452.75 & 8.461 \\
\hline $\begin{array}{l}\text { Moderate } \\
\text { suitability }\end{array}$ & 7852.7 & 27.09 & 4816.83 & 16.615 \\
\hline $\begin{array}{l}\text { High } \\
\text { suitability }\end{array}$ & 16139.81 & 55.67 & 16878.42 & 58.222 \\
\hline $\begin{array}{l}\text { Very high } \\
\text { suitability }\end{array}$ & 3820.43 & 13.18 & 4447.66 & 15.342 \\
\hline
\end{tabular}




\subsection{Commercial Land-use Suitability Assessment}

Figure 11. AHP weights of land-use suitability assessment for commercial land-use

4.4.1 General AHP for Commercial Land-use: For commercial land-use, the most important criteria identified was Compatibility to the surrounding land with a weight of $31.43 \%$, among which $12.59 \%$ accounted to being closer to urban centres and $10.17 \%$ to the existing growth area. The experts argued that there should be enough buffer between the commercial districts and residential areas to avoid crowd and noise. Existence to infrastructures was ranked the second priority (27\%), among which roads (10.3\%) and drinking water (7.9\%) were identified as the most important facilities for commercial land-use. The population density was ranked as the second most influencing criteria with weight $23 \%$. With a greater number of people there is more need for facilities like shops, and markets, hotels, hospitals, so on. The second most influencing factor was for commercial land-use was to be located near urban centres and existing growth areas or commercial and residential areas.

4.4.2 Multi-hazard AHP for Commercial Land-use: Avoid proximity to natural hazard accounted for $17.24 \%$ of the total influence weight. Like residential and industrial land-uses, flood $(5.22 \%)$ was considered the most crucial hazard followed by a landslide and then an earthquake. A reason for this could be that the flood events are more frequent than earthquakes. Sea level rise $(0.153 \%)$ was considered the least important because the increase in sea level is very slow and the degree of threat to commerce and industries is yet to be known. The change is weights of factors in commercial land-use are like the residential land-use, because of the similar selection of factors and grade classes.

\subsubsection{Commercial Land-use Suitability Maps:}

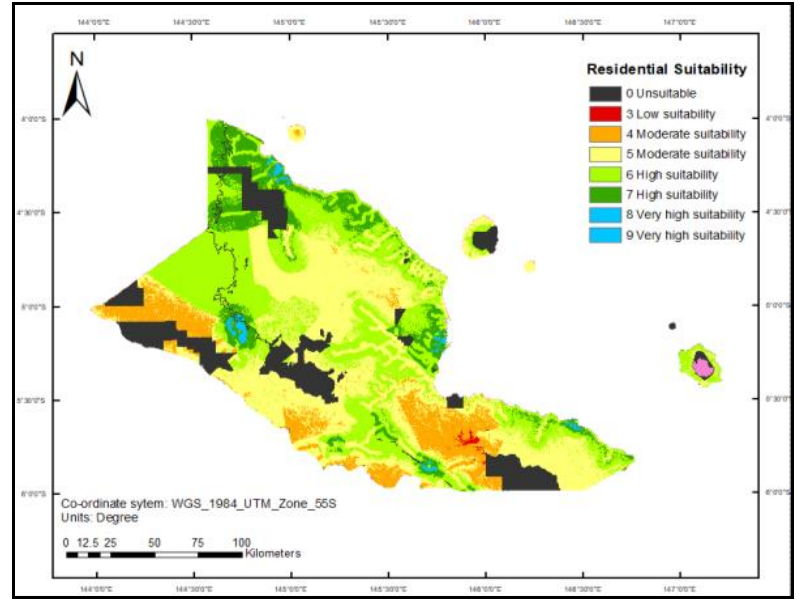

Figure 12. Commercial land-use suitability maps of General AHP

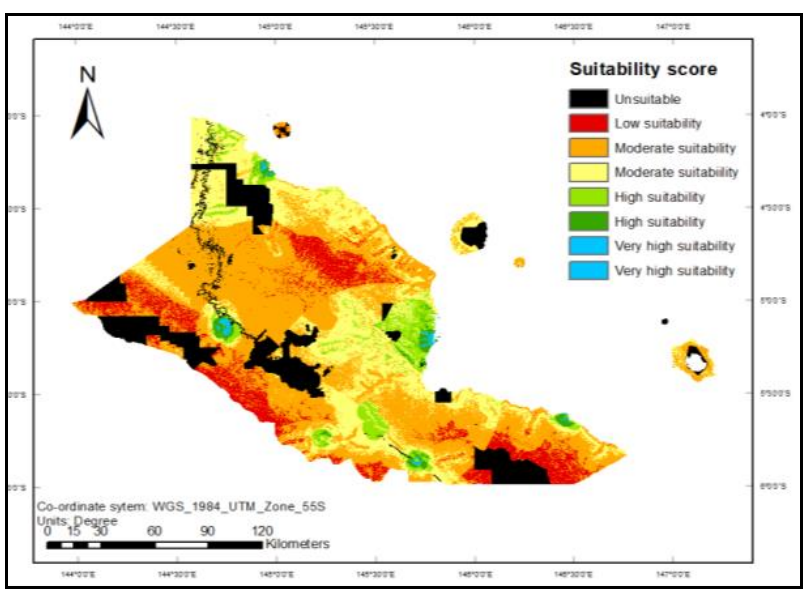

Figure 13. Commercial land-use suitabiluty maps of Multihazard AHP

Table 4. Agricultural land-use coverage for different degree of suitability

\begin{tabular}{|l|c|r|r|c|}
\hline \multirow{2}{*}{$\begin{array}{l}\text { Suitability } \\
\text { Class }\end{array}$} & \multicolumn{2}{|c|}{ General AHP } & \multicolumn{2}{c|}{ Multi-hazard AHP } \\
\cline { 2 - 5 } & Sq. Km & $\begin{array}{c}\% \\
\text { Coverag } \\
\mathrm{e}\end{array}$ & Sq. Km & $\begin{array}{c}\% \\
\text { Coverage }\end{array}$ \\
\hline Unsuitable & 3742.754 & 12.91 & $\begin{array}{r}3946.27 \\
2\end{array}$ & 13.613 \\
\hline $\begin{array}{l}\text { Low } \\
\text { suitability }\end{array}$ & 3736.5 & 12.89 & 3152.61 & 10.875 \\
\hline $\begin{array}{l}\text { Moderate } \\
\text { suitability }\end{array}$ & 9657.173 & 33.31 & $\begin{array}{r}19928.3 \\
07\end{array}$ & 68.742 \\
\hline $\begin{array}{l}\text { High } \\
\text { suitability }\end{array}$ & 11270.23 & 38.88 & 1845.8 & 6.367 \\
\hline $\begin{array}{l}\text { Very high } \\
\text { suitability }\end{array}$ & 585.239 & 2.02 & 118.91 & 0.410 \\
\hline
\end{tabular}

\section{DISCUSSIONS}

\subsection{Shift in weight between General and Multi-hazard} AHP

Existence of infrastructure, particularly road, highly influenced land-use decisions the most. The slope is also a highly 
determining factor for land-use development particularly, due to increased challenges in the construction of infrastructure in steep areas and high construction cost. Elevation was not thought to be as important as slope except in agriculture, because the climate is highly influenced by the change in altitude.

The comparative assessment demonstrates that there has been a shift in influence weight on all criteria and sub-criteria once hazard was introduced into the model. The reduction in the hazard scenario was proportionate to its weight in General AHP scenario.

The comparison of residential suitability maps with and without hazard shows that there was a significant change in the land-use suitability score, once the hazard component was taken into consideration. There has been a substantial reduction in the percentage of land with high and good suitability. The percentage of unsuitable land has increased. The portion of land that was initially suitable due to the presence of infrastructures, good land topography, good surrounding and so on has decreased because it was exposed to one or more hazards, because of which the overall suitability score of the area decreased. This has been depicted in the comparison below. The changes in the suitability score in the highlighted region has been attributed to the hazard exposure in the area

\subsection{Validation by comparison with existing scenarios}

In agreement with the land-use suitability assessment, the spatial risk to different hazards was also observed in Madang province. Studies of past events reveal that Madang has been affected by a 7.0 Magnitude earthquake On November 1, 1970, and 5.9 Magnitude earthquake on March 3, 2019. Local newspapers have also reported been earthquakes of magnitude 3.0 or greater nearby that area which has caused light damages of building and other structures. Through the research, it was found out that the study area has not experienced an earthquake of 8.0 Magnitude or more till date. Major damage or destruction due to earthquake-related hazard hasn't been reported so far. However, risk assessment shows that some of the sites within the study region have a possibility or earthquake and liquefaction (Jana, T. S., 2016). This information is to be taken into consideration and early strategic planning.

Madang is highly vulnerable to volcanic eruptions with the focus on Manam Island. Some major volcanic events in Manam island happened during October-December 2004 which had displaced more than 10, 000 people and affected many more after its last massive eruption. Some other eruptions are dated back to January- February 2005, January 2006 and December 2018. This validates the findings of the study as well.

\subsection{Multi-hazard assessment and perceived risk on different land-use}

Flood hazard received the most important factor in land-use planning residential, industrial, and commercial land-use. Sea Level rise was the least severe hazard in all the four land-uses. It was found that landslide and earthquake ranked second and third for the most threatening hazard for residential and commercial application whereas, for industries, the earthquake was found to be more threating than landslides. Residential, commercial, and industrial land-use was thought to have a greater risk due to multiple hazards. Whereas agricultural sector was thought to be more resilient to hazards. This is because unlike the infrastructures and housing sector, the loss due to agriculture is the easiest to recover.

However, among others, floods, and volcanos (ash deposition) were identified are the most crucial hazards for agricultural land-use. Though agricultural crops might be affected due to flood, it highly depends on the timing of flood event. Eventually, flood and volcanos would benefit the farming sector because it carries different minerals that make the soil more fertile, with the flow.

\section{CONCLUSIONS}

In this paper we have developed a method to use multi hazard maps to make risk informed decision in urban planning and land-use development. We integrated multi-hazard approach in an existing land-use suitability assessment tool. We applied this methodology to check the potential suitability for land development for Madang Province, Papua New Guinea was assessment. We produced land-use suitability maps by using multiple natural hazard maps and geological and social parameters. The suitable areas for residential, commercial, industrial and agricultural land-uses was generated. The comparison between the land-use suitability maps that were produced with hazard maps and without hazard maps lead to discrepancies. This can be attributed to the fact that in most cases, the generated practice is that only geographical, social and economic parameters are used for urban development, whereas in our study, natural hazards, were also quantified and considered.

The application of this methodology for land-use planning determines the potentially suitable sites that are susceptible to natural hazards or not. So, specific land-use for each area (residential, commercial or industrial areas) can be determined. Furthermore, it can be useful in the verification of the present urban trend. It is possible to check which sites of the existed urban pattern have been developed in vulnerable areas to natural hazards.

Conclusively, it is demonstrated that it is possible to adapt a multi-hazard prospect into existing land-use planning tools particularly land-use suitability model. Engineers, urban planners, and policymakers can enhance the result in developing suitability evaluation studies, to come up with the most beneficial use of land, along with the conservation of natural resources and the protection of human lives from natural hazards.

However, this model does not come without its limitations. Since this study focuses on a spatial analysis of land-use suitability, the criteria that could have been spatially presented have only been considered. All the aspects of land-use planning decisions have not been covered in this study, for example, the property value, neighbourhood and population income which highly affect land-use decision. The hazard maps that were used in this research belonged to different return periods, which might have resulted in overestimation and underestimation of hazard risk. It is advised to consider hazards over the same return period.

This study also acknowledges some deficiencies in the output of the model. Since the study area is quite large and the population density is less and scare, true demographic data has not been depicted well in the output. Therefore, it is advised to confine the study to a smaller area, for example, city-level or 
town rather than provincial for better accuracy in comparison of different land-use.

Lastly, this model was successful in depicting the knowledge of experts by producing sensible output maps. However, it has not incorporated the view of local people of Madang province. Including local experts from the study area, will help to identify the natural hazard hotspots in the map and give genuine recommendation on hazard risk reduction through informed decision making.

\section{REFERENCES}

Agarwal, C., Green, G. M., Grove, J. M., Evans, T. P., \& Schweik, C. M. (2002). A review and assessment of land-use change models: Dynamics of space, time, and human choice.

Anderson, J. R., Hardy, E. E., Roach, J. T., \& Witmer, R. E. (1976). A land-use and land cover classification system for use with remote sensor data. Professional Paper. doi:10.3133/pp964

Antunes, P., R. Santos and N. Videira, 2006. Participatory decision making for sustainable development-The use of mediated modelling techniques. Land-use Policy.

Bathrellos, G. D., Kalivas, D. P., \& Skilodimou, H. D. (2008). GIS-based landslide susceptibility mapping models applied to natural and urban planning in Trikala, Central Greece. Estudios Geológicos, 65(1), 49-65. doi:10.3989/egeol.08642.03

Bathrellos, G. D., Skilodimou, H. D., Chousianitis, K., Youssef, A. M., \& Pradhan, B. (2017). Suitability estimation for urban development using multi-hazard assessment map. Science of The Total Environment.

Beinat, E. and P. Nijkamp, 1998. Multicriteria Evaluation in Land-Use Management: Methodologies and Case Studies. Kluwer Academic Publishers, Dordrecht, Netherlands, Pages: $17-31$.

Cheng, J., \& Bertolini, L. (2013). Measuring urban job accessibility with distance decay, competition and diversity. Journal of Transport Geography, 30, 100-109. doi:10.1016/j.jtrangeo.2013.03.005

Carpignano, A., Golia, E., Mauro, C. D., Bouchon, S., \& Nordvik, J. (2009). A methodological approach for the definition of multi-risk maps at regional level: First application. Journal of Risk

C Sun (2016). Urban Land Development for Industrial and Commercial Use: A Case Study of Beijing. MDPI Sustainability 2016

Dai, F., Lee, C., \& Zhang, X. (2001). GIS-based geoenvironmental evaluation for urban land-use planning: A case study. Engineering Geology, 61(4), 257-271. doi:10.1016/s0013-7952(01)00028-x

Delmonaco G, Margottini C, Spizzichino D (2006) ARMONIA methodology for multi-risk assessment and the harmonisation of different natural risk maps. Deliverable 3.1.1, ARMONIA

Dilley, M., Chen, R. S., Deichmann, U., Lerner-Lam, A. L., \& Arnold, M. (2005). Natural Disaster Hotspots. doi:10.1596/08213-5930-4
ESRI, 2011. ArcGIS 9.2-10, Redlands, California, USA, $\langle$ http://www.esri.com/software/arcgis/index.html $\rangle$

Galderisi, A., \& Menoni, S. (2016). The " State of DRR at the Local Level " A 2015 Report on the Patterns of Disaster Risk Reduction Actions at Local Level 1 Improving the Role of Land-use Planning for Reducing Existing and Future Risks (Working paper). doi:10.13140/RG.2.2.26376.62725

Halden, D., Jones, P., \& Wixey, S. (2005). Accessibility analysis literature review. London: University of Westminster

Jana, T. S. (2016). A GIS Based Approach into Delineating Liquefaction Susceptible Zones Through Assessment of SiteSoil-Geology-A Case Study of Madang and Morobe Province in Papua New Guinea (PNG). International Journal of Innovative Research in Science, Engineering and Technology, 5(5), 6616-6629. doi:10.15680/ijirset.2016.0505003

Kappes M (2011) Multi-hazard risk analyses: a concept and its implementation. PhD thesis, University of Vienna

Ohri, Anurag, Prabhat Kumar Singh, and Priyanka Kumari Singh. "Spatial Multi Criteria Analysis for Siting Industries."

Rengers, N., Soeters, R. and Westen, C.J. Van (1992) Remote sensing and GIS applied to mountain hazard mapping.Episodes, Vol.15, No.1, March 1992, pp.36-45.

Saaty, T.L. (1980) The Analytic Hierarchy Process, New York: McGraw Hill. International, Translated to Russian, Portuguese, and Chinese, Revised editions, Paperback (1996, 2000), Pittsburgh: RWS Publications.

Super Decisions. (2019). Creative Design Foundation.

Van Westen, C.J. (1993) Application of Geographic Information Systems to Landslide Hazard Zonation. ITCPublication Number 15, ITC, Enschede, The Netherlands, 245 pp.

V Gallina (2016). Thesis: An advanced methodology for the multi-risk assessment. An application for climate change impacts in the North Adriatic case study (Italy). Accessible at http://dspace.unive.it/bitstream/handle/10579/5613/8240261168027.pdf;sequence $=2$

YA Bun (2016). Community Forestry benefits customary landowners: Case study on Madang Province Papua New Guinea Accessible at https://rightsandresources.org/wpcontent/exported-pdf/madangpapuanewguineacfecasestudy.pdf

Yang, F., Zeng, G., Du, C., Tang, L., Zhou, J., \& Li, Z. (2008). Spatial analyzing system for urban land-use management based on GIS and multi-criteria assessment modeling. Progress in Natural Science, 18(10), 1279-1284. doi:10.1016/j.pnsc.2008.05.00 